\title{
IJTARP
}

International Journal of Transactional Analysis

$10(1), 21-39$

https://doi.org/10.29044/v10i1p21

Research \& Practice

This work is licensed under a eative Commons Attribution International License.

\section{Script Drama Analysis II}

\section{(C) 2019 Stephen B Karpman, MD}

\begin{abstract}
This paper completes the original Script Drama Analysis article (Karpman, 1968) that first introduced the Drama Triangle, Role Diagram, and Location Diagram into TA script literature. As did the previous article, this script theory paper also creates 'as many new ideas as possible' to continue Berne's legacy of invention by brainstorming as he taught his followers in his weekly Tuesday night seminars 'Think Tank' in San Francisco in the 1960s. (Karpman, 2014).
\end{abstract}

New game and script theory are woven into novel combinations, to open doors and inspire additional new script theory. Included are: a) 15 new scripting drama triangles including the Palimpsest, Redecision, Transference, Freudian, Existential, Miniscript, Biodynamic, and Darwinian Drama Triangles; b) $A$ family games analysis including the child's Redecision Triangle, the Script Game, Script Scene, Script Scene Imago and Dysfunctional Family Analysis; c) Two new script formulae for the Script Game Payoff; d) Three new internal and external Script Energy Drive Systems; e) Three new script reinforcement systems: Script Formula G, Script Formula P3. and a Miniscript Drama Triangle; f) A new three-cornered Darwinian instinct; g) Six new Existential Continuums; and h) Four combination three level script teaching diagrams.

\section{Three Family Drama Triangles}

To get started, we open with a new model that merges scripts and games into a single diagram for the first time in transactional analysis literature.

The drama triangle (Karpman, 1968, 1973) offers the theory link because it is a visual, a diagram. In Eric Berne's theory-making requirements, he taught his followers to create simple scientific diagrams using Occam's Razor of Scientific Parsimony to reduce psychological patterns to their unifying basic core. Berne's cardinal theory-making mandate was "Don't say anything that you can't diagram." (Karpman, 2014).
In this diagram, the 'games people play' of today can be visually linked to the 'games people played' in the childhood family, as illustrated in the four linking regression diagrams below, Figures 1, 2, 3, 4.

By nesting a smaller family drama triangle inside the larger space of a today's drama triangle, both games and script, past and present, are linked visually in a single diagram using connecting arrows, and confirming the old adage 'a picture is worth thousand words'.

The first three regression triangles below illustrate the script connections that are triggered and baited between the past and the present. The fourth diagram, the Redecision Triangle, makes that same point but adding in specific early childhood life decisions into the smaller triangle, to be placed directly along the PRV positions in the child diagram.

The TA position illustrated here is that the games of today originate in the games of childhood. This can be illustrated by directional arrows connecting the drama triangles of the present scene to the drama triangles of the family scene in the diagrams.

\section{The Protocol and Palimpsest Triangle}

This first of the three triangles here refers to Berne's naming the childhood scripting the protocol and the later script manifestations, the palimpsest (Berne, 1966). The games of the past and the games of the present fluctuate back-and-forth as shown with bidirectional arrows.

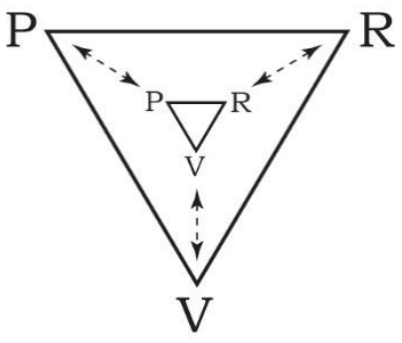

Figure 1: The Protocol and Palimpsest Triangle 
The Transference Triangle

This shows the arrows moving only in an outward direction, illustrating that the games of the unconscious and subconscious are constantly striving for expression, as referred to by Freud as 'the return of the repressed'. The drama triangle, simply used, can represent all the games played.

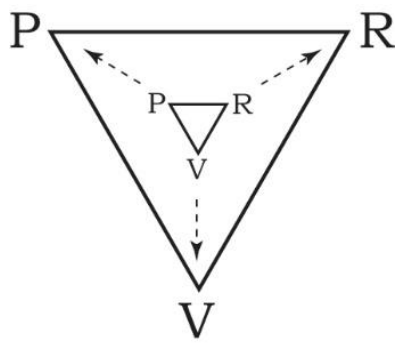

Figure 2: The Transference Triangle

Under pressure, the games buried in transference dramas find their outlet in social settings, in dependent relationships, problems with authority or partners, political arguments and others, and those triggered by a psychotherapist 'acting out in the countertransference.' Both transference and countertransference are openly discussed in the relational therapy approach and others, usually as fantasies and feelings rather than games.

In the 'Transference Games' (Karpman, 1991), the arrow triggers outwards. Unresolved victim events, projections, attributions, and instinctual memories in the id are all fighting for outward expression. They seek a setting with a suitable game-playing partner and only need the script signal (Berne, 1964) to begin. This is an attempt at the final catharsis and is triggered over and over again throughout life in the Freudian repetition compulsion, or in TA as an active script reinforcement game, as discussed below.

The illustration may also be helpful for teaching purposes in visualising Freudian catharsis in relational and traditional 'Family of Origin' work, and others.

\section{The Rubberbands Triangle}

This has the regression arrow pointing in the other direction, inwards, showing that a current trigger, perhaps a therapist countertransference, socially has 'snapped' a person back into an old experience, as would a rubberband. This flashback is what Berne (1966-1970) (and later Kupfer \& Haimowitz, 1971) called rubberbands - referring to Penfield's (Penfield and Jasper, 1954) classic work on electrical brain stimulation that appeared to recreate the actual experience of a forgotten earlier scene.

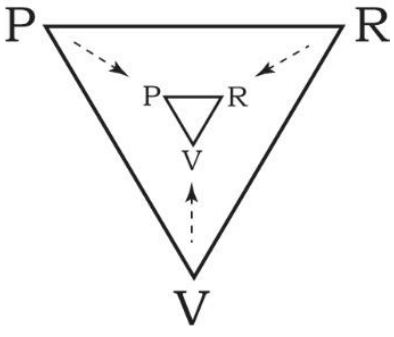

Figure 3: The Rubberbands Triangle

\section{Variations}

Design issues. Note above that the connecting arrows are drawn with intermittent dotted lines in either direction, illustrating hesitant or infrequent expression. For theoretical, teaching or research purposes, in certain situations the lines could be drawn as in Figure 4 below as a) blocked by specific barriers (that have a specific name, time and place); b) fully connected heavy straight lines which could signal unimpeded script acting out or even uncontrolled psychotic expression; and c) wavy arrow lines which could represent the existential fluctuations of life events that continually alter the script destiny in unpredictable ways. Any of these can connect any of the three corners of the triangle, perhaps in novel combinations.

Visual aids. These regression drama triangles are visual aids that can be also used as educational tools in organisational and rehabilitation settings to increase interest and belief that there are family origins of behaviour.

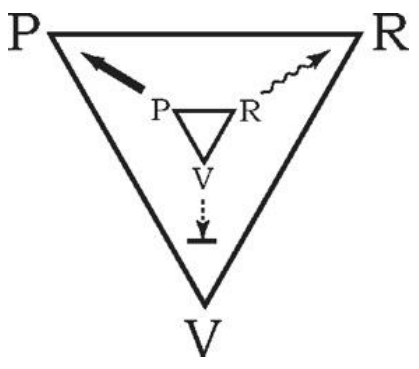

Figure 4: Transference Drama Triangle, Variations.

\section{Redecision Script Therapy}

Early in the days of transactional analysis, redecision therapy was developed by Bob and Mary Goulding, close colleagues of Eric Berne, at their international training centre on Mt. Madonna in Northern California (Goulding and Goulding. 1976, 1979/1997). They applied Berne's recommended Occam's Razor principle to finding a single point in childhood at the core centre of the life script. 
This widely used TA treatment of scripts uses gestalt therapy techniques to reactivate the key traumatic experience of early childhood when the child's script decision was made. In the treatment process, the therapist facilitates the client's re-experiencing of the traumatic early scene by systematically using twochair serial gestalt regressions, going step-by-step back in time to re-experience similar occurring situations.

Eventually, using Occam's Razor principle, this gets the person emotionally back to the single most defining childhood scene to re-experience the early family trauma in the present. This is done in a protected therapeutic setting that provides a new opportunity to re-decide that decision and get group support for that change, thereby deconstructing the script that is no longer useful to the client.

All this happens in what I call the Script Game happening during a family Script Scene. The child's script decisions have to be made in consideration of the Persecutor (P), Rescuer (R), and Victim (V) positions of the family members in their own games, and factoring in the level of neglect, threat and alienation ahead. A young child has to solve this within the family in the best way they can, considering limiting injunctions already in place, and considering their brain development at their age, and with no way of knowing the effect it will have in later life.

By using the game model, the complicated intense emotions of a three-sided psychological game can illustrate the full tenacity and complexity of the script game and script decision.

But later in life, with this knowledge, this triple PRV layering can be unravelled when entering in-depth psychotherapy. It may show particular tenacity in all three corners when reaching the impasse point in redecision therapy. This can be seen when the needs of the Free Child have to confront the needs of the Adapted Child in the two-chair gestalt regression redecision exercise.

To look at this we can use the Redecision Triangle in Figure 5. This is a new illustration for TA redecision theory literature, demonstrating three new points to consider in the therapy process. For a complete redecision escape we may need to investigate all three roles of Persecutor, Rescuer and Victim in everyone involved in the script game as played out in the family script scene.

The larger outside drama diagram represents the other family players in the game. In the middle of that is placed the little inner drama triangle to illustrate what is going on within their child during the wider family drama.

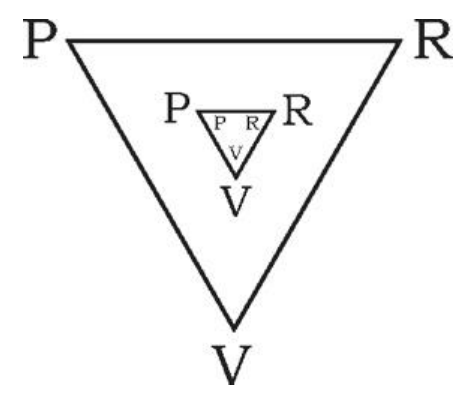

Figure 5: The Redecision Triangle

On the inside, the PRV letters represent the three psychological level roles of what the child is privately experiencing, unknown to the parents.

On the outside of the little child's triangle are the three PRV social level roles in their reaction to the parents, as the child has to resolve their script positions within the larger family context.

This six-sided model of the entire game opens up explorations into the depth of the game and includes the many 'advantages' of game analysis (Berne, 1964). The therapy may be complete when all six sides are addressed successfully.

\section{The Child's Inner PRV. The Psychological Level} Game

For example, we do a step-by-step review of the redecision process as used in therapy, using the redecision drama triangle. When finally reexperiencing the primal script scene, the psychological level of the child is exposed.

Step \#1, The regressed child in therapy is asked "How did you feel at the time?" (Victim), and then -

Step \#2 "What did you decide about life to protect yourself?" (self-Rescue) and to put another layer on their denial, taking it a step further to -

Step \#3, A move next over into a more fixed energy (Persecutor) position converting it all to a life script limiting but protective Don't decision from among some of the 13 injunctions identified by Goulding and Goulding, such as Don't Want, Don't Feel, Don't Think, Don't Act, etc.

On the inside of the child's triangle, a neglected child may have felt "I am all alone. No one listens, no one cares" (V). They may then have decided to Rescue themselves with the cover-up position: "I'll be OK if I go it alone in life" moving up to (R). But to further lock it in they make solid lifetime Don't injunctions, perhaps with a Don't Be Close $(P)$ injunction. That protective isolation may one day lead to a problem with loneliness later in life, which may bring them into psychotherapy. All of the injunctions are limiting, and all can be redecided. 
The Child's Outer PRV. The Social Level Game Taking it a step further into the redecision drama triangle diagram above, we see now how the child has to weave their new self into their relationship with the family.

The outside PRV of the child's triangle shows the choices that are available in connecting their new script positions to the ongoing family drama, in whatever roles are available for them. This is in consideration too of the roles that any competitive or compliant siblings may have already taken for themselves or that have been assigned by the parents.

In the example above the child applies the Don't be close resolution for three family reasons:

1. Surrender (Victim) position: The powerless Victim child eventually decides to yield without resistance to the unstoppable family pressure; or as -

2. Pleasing (Rescuer) position: take that role to please the family members by being quiet and invisible for them; or as -

3. Revenge (Persecutor) for revenge to continually disappoint the parents by isolating themselves from any rewarding contact and success the parents could enjoy and be proud of for their offspring, and later, to fail in life, to prove to the world that it was a bad family of origin and blaming their parents to others with the game's external social advantage of "Look what they made me do." and the internal psychological advantage of "I got revenge and I am blameless."

The Parents' PRV. The Outer Triangle

With advanced in-depth family therapy, the parents also can reveal their own drama triangles with their own three-sided inner psychological levels of experiences, and their own three-sided game roles in their social level outer triangle. The drama of the games can include switching roles around among the family members, forming dyads and triads of loyalty and betrayal with each other, which can eventually seem too entangled, enmeshed, and unsolvable in a typical 'dysfunctional family.'

We can talk of the goal of a complete drama analysis of the family, but the six-sided complexities (6 inner and outer PRV of child and 6 inner and outer PRV of each family member) presented above of a family script game may never need to be explored during the emotional, gestalt-based redecision process. In complex second- and third-degree scripting, however, and in therapy impasses, the full expression of all six Persecutor, Rescuer, and Victim roles present in transactional games of everyone in that room may need to be explored. A game can include unlimited players. Some may not live at home.

\section{The Script Game}

Games create the script. The redecision process is the treatment of a script game. Those family games can be named. The family roles can be named. The personality types can be named. Siblings can read about them and discuss them by name.

In the family setting, where alliances and alienations have players frequently switching around in the drama triangle, we can find the 'favourite family game' with a name right out of Berne (1964) - names such as Let's You and Him Fight, Here We Go Again, If It Weren't For You, Courtroom, Furthermore, and Blemish. Additionally, one can name who were the Persecutors, Rescuers, and Victims in their family with a name people can look up and read about.

This can bring someone welcome relief to find out they are not alone in those games, which have been written up in print along with others. The new insights and viewpoints can be discussed then with their siblings, parents and therapists later in life.

Much of the negative scripting can be prevented if treatment comes early and the answers arrive in time during childhood.

Family insight can be obtained by the therapist using the Parent Interview (McNeel, 1976). This is a widely used and effective way of looking into the roles of parents in childhood. To find the roles and mood at the time of the scripting, direct questioning may be used, asking questions such as 'What do you think your parents' motivations were?" - which in the drama triangle might uncover both the social and psychological level motivations at all three corners (PRV) of each parent's (and sibling's) personal drama triangles.

People read books and seek insights to know if there were any games going on when they were growing up, including knowing the name of the games played by the people they grew up with. Family answers could sometimes be unexpected, like the surprises one might find in family DNA tests with relatives.

In summary, we put diagrams and useful names that we can remember to what is only emotionally experienced. Science names things so they can be studied further and taught. By putting what Berne called a 'handle' on a game, that name can be held for insight and interpretations at a later date. This can be used for Adult insight in treatment contracts called 'Adult control of the Child.'

\section{The Script Scene}

This name gives a useful 'handle' in defining where and when childhood traumas are played out. It will be an actual setting with a date in history that could have been "photographed and tape recorded," which was Berne's definition of social reality. This can be 
renamed the script scene wherein the script game is created and the child's script positions and script decisions are made, presenting four avenues of exploration in therapy. The name gives welcome clarity to what had once been suppressed or experienced nonverbally.

\section{The Script Reinforcements}

The script scene is recreated over and over later in life in the Freudian repetition compulsion to get the same payoffs over and over. Each payoff safely re-seals once again the family traumas behind the protective script positions and script injunctions. This ongoing reinforcement is illustrated in the Script Formula $G$ later in the paper.

\section{The Script Imago}

People carry in their head all the family script players in what can be called the script imago illustrated with the role diagram in my original paper (Karpman, 1968). Throughout life the original family roles are projected over and over again onto similar players in order to recast the early script scene. The real or imagined recasting of the roles sets up the reinforcing script game that gets to the script payoff, the script reinforcement. Nine steps to reinforcement are spelled out in the Script Formula $P 3$ described later in this paper, and in the briefer Script Formula $G$.

For an example, a personnel officer may repeatedly hire all the roles in their script imago for their family script scene in order to watch it played out in the office before them - for a resolution that never comes. Or a person may see the world through a limited number of roles in their head that represent each of the original family members. Or more limiting, an individual with borderline personality diagnosis may see people only as their Persecutors or Rescuers, with themselves as the needy or harmed career Victim.

\section{Dysfunctional Families}

Defining the Family as a Single Unit Dysfunctional family is a common term used to describe a toxic family environment in which a child is raised. If the script games are frequent enough and the drama is heavy enough and there are enough threats of dire consequences and ostracisation, noone comes out unscathed. In a TA game of pecking orders, a dysfunctional family will create a pecking order of power and influence, in which the sickest person is at the top calling all the shots and is listened to, and the sanest person, to whom no-one listens, is at the bottom. (Karpman, 2014). This is also seen politically in what is called a dysfunctional organisation, in which the dominant self-defeating projections of several dysfunctional families become enmeshed. Innovation and progress become limited and they cannot hold onto their best talent.

\section{The Outsider Triangle}

One feature of a dysfunctional family is the absence of Adult to Adult problem-solving communications. Then the family secrets go unchallenged and unspoken rules and unspoken penalties are all kept well hidden by collusion. Trading stamps, pettiness, blame and swings around the drama triangle can quickly increase to the level of second- or third-degree games and replace the more desirable empathic and logical communication of other families. The consequences may be quite unfortunate for the child whistle-blower who calls out the favourite family secrets or spotlights the 'elephant in the living room' and gets ostracised, to wind up as the new outsider in the outsider triangle (Karpman, 2014).

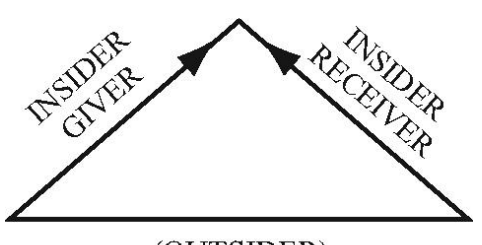

(OUTSIDER)

Figure 6: Outsider Triangle (not a drama triangle)

\section{The Identified Patient}

In classic family therapy, the entire family is treated as a unit. This is to avoid the singular focus on the identified patient (Karpman, 2014), who overtly plays the disruptive Persecutor damaging the family harmony, but covertly is the Victim of the entire family dysfunction, and more secretly is the Rescuer by sacrificing themselves to be the 'lightning rod' for attracting excess anger which serves to keep the rest of the family stable. This is a hard Rescuer position that they are reluctant to abandon. If their Rescuer position is threatened, they will escalate dysfunction to a level of insolvability as both Rescuer and Persecutor to maintain the status quo and be the designated target once again, but more resistant to change each time.

\section{Escalations in a Dysfunctional Family}

Dysfunctional family games can quickly escalate into family emergencies in four ways: 1) escalate to a greater number of players involved, 2) to a greater geographical area involved, 3) to greater consequences, embarrassment and expense to more people, and 4) with increasing levels of confusion, tenacity and insolvability. For example, a disruptive drunken alcoholic can create a violent scene, bringing in police officers, with urgent phone calls to relatives at night in far-flung corners of the globe. And do it often. (Karpman, 2014)

\section{Classic Family Therapy}

Redecision therapy may need to go beyond the client and include the dysfunctional family environment, with the treatment of the entire family game and not just of 
the one person in that family. Classic family therapy has the entire family in the office and taking the position that the client is only one symptom of a family disease. The entire family has to be treated as a single unit with a single interpretation, and with none going to an individual person, for instance addressing the family as a unit "There seems to be a problem in solving this."

In a family group therapy setting, the goal is to get the family to use TA language and for them to be discussing the drama triangle as a common language shared by the entire family. Eric Berne once advised on the use of TA terminology "You know your patient is getting better when they start using your language." (Berne, 1966 -70)

\section{The Family Coat of Arms}

Berne (1966 -70) suggested that the prevailing family mood could be placed on the 'Family Coat of Arms', written in Latin and placed above the fireplace (if there was one). To uncover this the therapist asks this one family question "What was the mood like to grow up in your family?' Some examples may include a Coat of Arms that reads an ominous 'Don't ever get your father mad!' or the freewheeling 'Yo, dude, do your own thing, baby;' or the Latin language variations of the 13 script decisions could be written up there as a menu to choose from.

\section{Defining the Family as Individual Members} Identities may be borrowed from favourite fairy tales and family stories. Stories told of others often enough may offer an appealing role for the child to copy in life. These heroes or villains may be stories about family relatives like uncles and aunts, with a rollcall of what to do or not in life, such as: "I'll never get trapped in a marriage like my mother," or, "You're going to wind up in prison like your father." A child is looking for a suitable role in life that will help them carry out their script decisions, and these sometimes come from stories told often enough at home or in the pages of available books, TV and movies.

There may be a favourite family fairy tale (Karpman, 1968) so often told that the child might decide on that story as a life course based on the players, locations and actions within it. To elicit this the therapist may simply ask "What was your favourite fairy tale growing up?" or "Who were your childhood good guys and bad guys?" An exciting escape script including travel to faraway places with new adventures may be elicited using the script location diagram (Karpman, 1968; Isaeva, 2011).

Egograms. (Dusay, 1972) There are common TA ways of defining the individual personalities of family members. A client learning transactional analysis will learn to define each of the relative personal strengths displayed by the family members by learning how to draw their egograms. A fascinating exercise in workshops is to get people to draw out the diagram of each other and of their parents and siblings and discuss these egograms - and then later with other family members. One novel exercise is to do overlapping egograms and see what is common and what is not in common there (Karpman, 1974).

Sweatshirts. Eric Berne often suggested that the opening thesis of a game could be announced on someone's sweatshirt. These could be read as Try And Stop Me If You Can or Let's Pretend I Care About You. To further clarify family identities, the client can be asked to name the parents' and siblings' sweatshirts - as well as their own! (Berne, 1972).

Drivers. (Kahler with Capers, 1974). For more awareness of who was in their family of origin, one can study the miniscript drivers of each family member in the process therapy model (Kahler, 2008). The drivers can reveal the six personality types there (Believer; Feeler, Thinker, Doer, Funster and Dreamer) of all family members with the ability to predict the future actions characteristic to these types. These same six types, in the same order, are later referred to as Persister; Harmonizer; Thinker; Promoter; Rebel; and Reflector (Imaginer). (Kahler, 2019)

\section{TA Script Treatments}

We have discussed at length a family games approach to the more popular redecision therapy. There are several other approaches in TA therapy but a review of those is not within the scope of this paper.

The in-depth family material presented here as arising in a family house of games is useful too in traditional forms of therapy as has been mentioned previously, such as many of the psychodynamically-oriented therapies and family of origin therapies.

\section{Is One Psychotherapy Model the Best?}

Psychotherapy methods vary with personality and with the therapist's training and location. Too often the benefits of each school are argued competitively, as if favouring the advantages of their favourite ego state in their own personality, with great loyalty to the assumed superiority of their training experience over all others. However, all are probably effective with care and training.

Different training institutes, in this age of diversity, still may believe that theirs is the best while politically minimising or even punishing the others by labelling them and denying access. This competitiveness deprives their own trainees of role models and permission to explore other methods of psychotherapy, thus limiting future innovation. Four competitive positions can be arranged in the four quadrants of the Bias Box (Karpman, 1975), where the 
axes are subjective versus objective, and fun versus serious - with TA as objective and fun.

\section{Bernian treatment models}

In the beginning, Berne outlined the four basic stages of transactional analysis theory: 1. Structural, 2. Transactional, 3. Game, and 4. Script Analyses. Steiner (Steiner, 1966) advanced script theory with his breakthrough three level transactional script matrix, later upgraded by Berne (1972) to a script apparatus. However, these early models dealt with transactions, permissions and injunctions, but not with any story line. Goulding and Goulding (1976, 1979/1997) expanded the injunction list to a crisp list of 12 that were developed during the many years of use of their novel treatment approach, with Mary Goulding later adding the important unpublished 13th injunction, Don't Want/Need.

\section{A Script Story Line}

Without a story line in the early stages of scripting theory, this author introduced it by adding the roles, players and locations in the story, plus the drama triangle switches in the story over a time span. (Karpman 1968). This included the recall of the favourite childhood fairy tale, that offered a template for a story line. For example, the Cinderella fairy tale can be used as a template for a Rescue script - for both men and women.

\section{Six Time Scripts}

Berne further added a clearer timeline by adding six predictable patterns for the onward progression of the script story; the Never, Always, Until, After, Over and Over, and Open-Ended scripts. Steiner (1974) later added three lifescript attitudes throughout the story line, the Mindlessness, Joyousness and Lovelessness scripts.

\section{Miniscript}

Kahler $(1974,2008)$ introduced a minute by minute system of reinforcing one's script story. He named five miniscript drivers residing within the Parent counterscript as false Rescuers that could keep reinforcing a negative script on a second by second basis. Six personality types emerged, each with their own drivers and their own script story. A timeline in his process communication model; for instance, could be: the Be Perfect driver of the Thinker personality type would form an Until script; the Be Strong driver of the Promoter type, as well as the Try Hard driver of the Rebel type, form the Always script.

\section{Remove Ego State Blocks}

To be free of one's negative script, and 'make your wildest dream come true' one needs to solve three consecutive sets of ego state blocks, in the Parent, Adult and Child. There are a separate set of blocks in each stage in three stages: \#1 No Dream, \#2 Dream
But, and \#3 Dream Yes. These stand in the way of one's wildest dream goal: three blocks to know you have a dream, three blocks to know where the dream is, and three blocks to stay free to keep doing it. (Karpman, 1985). For example, the blocks of Parent Putdowns; Adult Routine; and Child Conformity in the Stage \#1. No Dream; or the ego states blocks of Parent Principles; Adult Practicality; and Child Conformity in the Stage \#2. Dream, But.

\section{Developments of TA}

Before considering Bernian treatment models, it is worth noting how many other pioneering TA writers have contributed to script theory with their own original psychotherapy models.

For instance, several incorporated the writings of Wilhelm Reich with a focus on releasing early memories that were locked in protective body armouring, in a TA variation of Reichian bodyscript therapy (Cassius, 1975; Cornell, 1975; Childs-Gowell \& Kinnaman, 1978).

Several psychoanalytically-oriented versions of TA have emerged as relational TA, always united in TA with Berne by common knowledge and use of original Bernian TA ego states, with the integrity of his core theory protected by the ITAA Training Standards certification process. Pioneers include Helena Hargaden and Charlotte Sills (2002), and Richard Erskine who writes: "Life scripts are a complex set of unconscious relational patterns based on physiological survival reactions, implicit experiential conclusions, explicit decisions, and/or self-regulating introjections, made under stress, at any developmental age, that inhibits spontaneity and limit flexibility in problem-solving, health maintenance, and in relationship with people" (Erskine, 2010, p.1)

Relational therapists also use a different language from what Eric Berne taught, using a psychoanalytic base terminology with an intersubjective exchange with clients. The exploration of transference and countertransference experiences in relational psychotherapy were also described by Berne in his behavioural TA system, classically as crossed transactions using his ego state model, as described below.

\section{Transferences as Ego State Crossed Transactions}

We will use the ego state model to explain the crossed transactions in Figures $7 \mathrm{a}$ and $7 \mathrm{~b}$. In the diagrams, a) makes an Adult statement to b), which ends up either with the crossed transaction from the Child to Parent as transference, or from the Parent to Child as countertransference. Berne (1966) published the two diagrams to establish the link between the Freudian transference and countertransference theory with his own ego state transactional diagram. 


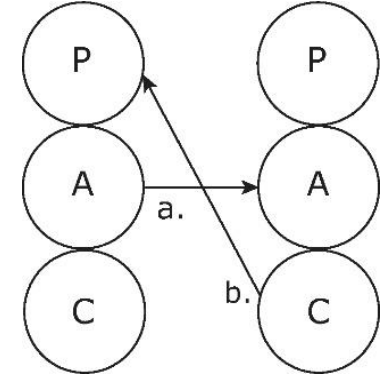

Figure 7a: Transference (Berne 1966, p.157)

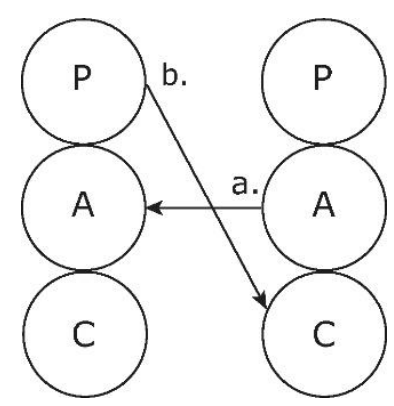

Figure 7b: Countertransference (Berne 1966, p.256).

\section{Projected and Introjected Ego State Diagrams}

Let us now continue the experiment here with novel ego state scientific diagrams, which is a purpose of this paper. Figure 8 combines the standard transactional diagram with the addition of two embedded drama triangles - one for the games of the regressed self and one for the games of the projected non-self. Referring to writings in redecision literature, it uses a modification of a redecision diagram (McNeel, 1976) but now includes the drama triangle to represent the occurrence within a two-sided script game. This continues the theory that the redecision process is also the treatment of a family game. This diagram can also be used for elaboration of the psychoanalytic TA relational work, to highlight the point that Child and Parent transference and countertransference reactions must be analysed within the context of an entire family game.

This combination diagram incorporates several psychological level schools of TA by illustrating both the introjected and projected selves of early games. In an ego state study for the redecision model, the diagram below is used to represent the psychological level of regression therapies with projections and introjections.

To take TA theory-making a step further and tie in additional theory possibilities, we could imagine inserting drama triangles within second- and thirdorder structural Child ego state circles and structural Parent ego state circles to imagine new structures with new possibilities in analysing what goes on deep within the earliest child during the establishment of script games. We can put a game triangle to represent

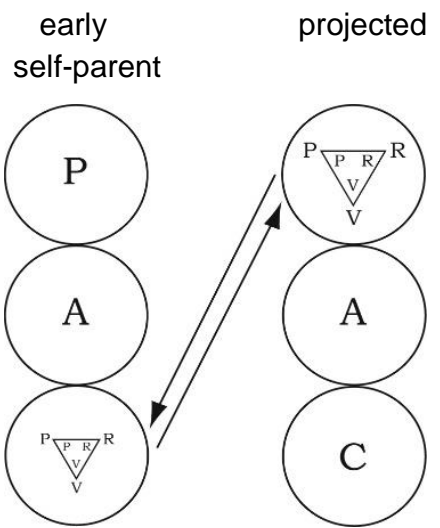

Figure 8: The Transference Game Diagram (redecision modified from McNeel, 1976, p.66).

games played within each of the six stages of the time structuring list. Similarly, the drama triangle can also be placed within functional transactional diagrams, as well as in various script and other known matrices and we can invent new ones, or superimpose one diagram on top of another just to see what happens and keep the brainstorming of theory development alive as Eric Berne wanted.

\section{Transference as a Game}

All the above transference diagrams can be used in the TA relational approaches of co-created and shared transference and countertransference therapy. A client who is a game player creates in therapy their favourite transference and countertransference game experiences, in collusion with the therapist, and can set up and project any one or more of three drama identities onto a therapist, with the goal of gaining their script payoff, sometimes without the therapist's knowledge. For example, three drama triangle variations of transference:

To misread the therapist as a Persecutor in their script game. In Persecutor transferences, the client may falsely assume or set up the therapist to be the actively critical or the passively disapproving parent from childhood, and in mistrust, act out, punish or delay revealing one's true self in therapy, if ever.

2). To misread the therapist as a Rescuer in their script game. The Rescuer transference here may be a projection of one's own parent who was passively too nice and permissive and who would never confront or set limits. This invites the client's Rebel Child to plugin the 'I can get away with anything' trick, which may include after-hours phone calls, never doing their homework, and not paying bills on time.

3). To misread the therapist as a Victim in their script game. In Victim transference, the therapist is dismissed as the incompetent Victim parent, errorprone, an untrained embarrassment not worth listening to - and pitifully ineffective in dealing with anger that will escalate. 
Similarly, the therapist in Countertransference could misread the Parent, Adult and Child, each separately in their client, creating three separate countertransferences to share.

\section{Berne TA Scripting}

\section{Autonomy}

Berne's TA focuses on the autonomy of the child. As incorporated into redecision therapy, the child is not a helpless victim as in most psychodynamic models, but makes aggressive, conscious script decisions of what to do about life. Classically here the child can use a conscious Adult decision to design defences for how they can distance themselves from the influence and impact of their family drama.

Traditional cause and effect thinking is reversed too in the Bernian autonomy-based philosophy. Rather than solely focus on the traditional early psychological level cause of the problem, the focus is also equally on the social level effect desired to reinforce this script, which goes far beyond traditional social level transference interpretations. In other words, one purposely plays a game within the social environment for the effect of advancing to the script payoff, a payoff that perpetuates the script's earliest protections all the while maintaining the multiple current advantages of a game (Berne, 1964). The Child is in charge, not the therapist, as the Goulding's taught, "The power is in the patient."

TA Psychological Level Treatment of Scripts. The Inner Self Drama Triangle (Figure 9) is a model to visualise how a person with new autonomy can convert personal negative game energy into positive game-free energy.

Classically, the three inner and outer corners of the drama triangle will present their energies in a positive or negative way, in keeping with basic TA ego state theory where ego state energy can be used in a positive or negative way.

People have a choice to keep either the positive or negative drama energies active within themselves, as determined by their new script redecisions, and in combination with available help, plus chance happy events in their outside world.

Life events or therapy may lead someone to decide "I'm going to have a more positive outlook in life." But with one caution: on any script decision, what if someone is just switching corners in the drama triangle? For instance, a decision to be positive could be used negatively as a weapon $(P)$ by holding a superior positive attitude over the lesser people around them. If that happens, then they would have only shifted roles within their drama triangle over to Persecutor but have not removed themselves from the drama triangle.
Technically, what is happening internally is illustrated: three positive choices one can make is to convert these negative three energies to their three positive uses to get out from the game triangle.

Looking at the example, we see the conversion of the natural aggressive energy of the Persecutor (-) from self-sabotage to self-determination and selfempowerment $(+)$; and the Victim absorption of the energy of self-pity (-) as self-acceptance (+), and the protective energy of denial and self-delusion (-) converted to self-love $(+)$ and self-worth at the inner Rescuer corner.

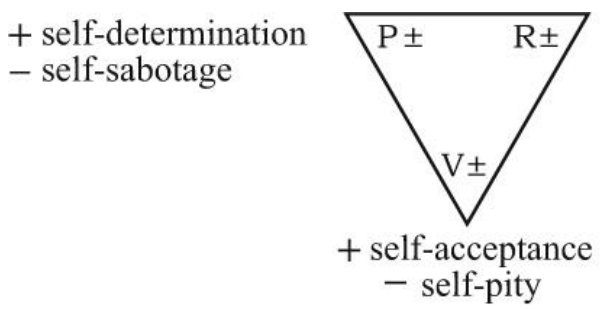

self-love + self-delusion -

Figure 9: The Inner Self Drama Triangle (Karpman, 2009 p.112).

\section{TA Social Level Approach Treatment of Scripts. The Compassion Triangle}

The Inner Self Drama Triangle offered a psychological level way of exiting games, by choice. within yourself. The Compassion Triangle 2.0, (Karpman, 2014) gives a TA social level way of exiting the script as conducted in social partnership with others.

\section{Give Apology Give Appreciation

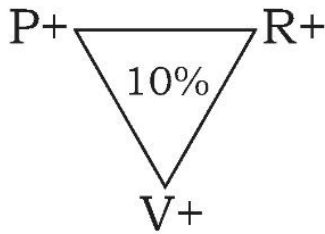 \\ Give Sympathy}

Figure 10: The Compassion Triangle 2.0 and the 10\% Solution. (Karpman, 2014, p.104)

\section{Three New Survival instincts}

From the descriptions of the Darwinian Triangle (Figure 15), we can confirm the theoretical position of the compassion triangle - that all three roles in the drama triangle originated in archaeological times as three distinct survival instincts that forevermore can be triggered automatically as survival reflexes, in alarm and stress situations, in all players emotionally involved in the game.

In therapy we need to search for all three corners of the game and their three motivations. This gives us three new options and talking points for dismantling the game or six options in couples therapy. 
This new compassion triangle is one step advanced over the first drama triangle. The original drama triangle worked to give people a) awareness that there is a game going on and they are in it; b) there are known players taking roles and actions in the game; and c) new awareness that allows them to decide to quit the game and find relief.

The drama triangle told us what is happening, but did not look deeper into why it is happening. That is what the compassion triangle does. What are the unseen triple motivations of the players? Why are they attracted to the game? Do they stay in the game, trapped, because too many corners are involved, each needing its own discharge that the other will not let them have? The compassion triangle can reveal up to six motivations total in couples' therapy. This can be unravelled in a compassion triangle exercise, using the diagram for reference.

\section{The Compassion Triangle exercise}

Figure 10 shows a way of exiting games at the social level, with another person, using a compassion exercise in which two persons can participate. Partners take turns in the exercise; one accounts for and forgives each of the corners in the drama triangle in oneself and then in the other; they switch sides and do the same with the other. Someone needs to keep track if the exercise is being done correctly.

The steps in the compassion triangle exercise are as follows:

1. Looking at the diagram, when it is your turn, you offer for the other person's empathy and compassion:

2. An Apology $(P)$ for your role in the game, perhaps with explanations of your intent - but not excuses;

3. Appreciation $(R)$ of the good you meant by your actions;

4. Sympathy (V) from someone to feel your dilemma and limited choices in being stuck in the game;

5. With your best empathy, give your best three guesses as to what the other person must be going through in dealing with you in their three corners of the triangle.

Six feelings have been expressed by person number one. Switch sides and person number two reviews their three feelings in themselves and the other person.

What follows is considerable relief and good feeling in that six different feelings and views of the events are positively expressed by each person, with a total of 12 that are shared.

The $10 \%$ solution

The numbers placed in the centre of the compassion triangle allows for the ego-levelling Ten Percent Rule:
$10 \%$ of everything you say is true and $10 \%$ of everything you say is false. $10 \%$ of everything the other person says is true, and $10 \%$ will be false. And $10 \%$ of the World population will agree with you and $10 \%$ of the World population will disagree with you, and $10 \%$ of the World population will agree with the other, and $10 \%$ of the world population will disagree with them. To give an example of its use in couples therapy, a strong denial can immediately be met by the request, "OK now, tell us the minimum $10 \%$ that is true." (Karpman, 2014).

\section{The Wisdom Triangle}

This can be an alternative name for the compassion triangle, showing how one can exhibit a wider and wiser view of the world by automatically recognising all three sides of every issue. It takes practice.

It can also serve as an individual way of monitoring oneself and the three choices one has in any game situation, by considering three possibilities in oneself and considering three possibilities in another. It offers three fresh ways of interpreting public and political situations one is observing when others, the 'onethirders' are locked into only seeing one corner of the three. The goal is an instinctive knowing that there are three OK ways of looking at every situation, often ones that most people would not think of. This fairness is seen as wisdom and restraint.

\section{The Question Mark Triangle}

This is another variant (Karpman, 2014) that offers three possibilities to consider when trying to understand a puzzling event where there are no answers.

For example, if the puzzle is why someone left you and never gave a reason: were they being your Rescuer to protect you by keeping things from getting more hurtful; or acting as a Persecutor to get even with you, deservedly, for something you did wrong and did not admit or apologise for; or was the person just an innocent Victim in the situation without awareness of anything wrong going on - and you'll never know which one it is. But you will not be stuck on only one answer. For instance, from the three choices, if you only look through the Persecutor Window, there is a $66 \%$ probability that you are stuck with the wrong answer.

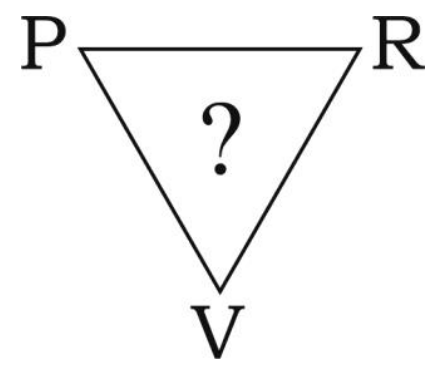

Figure 11: The Question Mark Triangle 


\section{Existential Scripts}

Now we move beyond the Bernian concept of script as a story line with a fixed destiny into one that is flexible and altered by a changing life course (Berne, 1972), and move into the uncharted waters of scripts as an evolving existential experience.

\section{The Four Fates: Father Time, Mother Nature, Lady Luck, and Tom Foolery}

We can speculate briefly on possible ways of diagramming existential pathways when the script plan is no longer set in stone. The absence of direction could happen when the Open-Ended script is reached, the last among Berne's six time scripts; or it could start in childhood with a Change Everything decision so nothing is ever fixed.

A free-floating script can unfold in unexpected ways influenced by the whims of the four fates of existential scripting, Father Time, Mother Nature, Lady Luck, and Tom Foolery (the unexpected Trickster - the fourth role in my original drama triangle). That is a Childfriendly list reduced to an easy four. Berne once Occam-razored scripts down to only one, saying that at the age of thirty a switch flicks on and you become like your parents (Berne, 1966-1970).

On being script free, does one become subjected to the winds of the four fates above? Is someone truly script free? Who scripted the fates? Was your freedom scripted? Can anyone be script free? Did your parents episcript you to be script free? Are you biologically patterned to have a script? Can someone only be script free temporarily?

\section{Scientific diagramming}

Now let us put left brain scientific diagramming to work to the ultimate challenge and see if the unpredictable flow of chance, existential experiences and life paths can be reduced to a simple diagram (for the sake of science).

One diagrammed approach we could brainstorm would be to create a diagram with plot points on two linear life continuums: a) one line would plot the new script decisions at each plot point in life; and b) on the parallel other line, would be plotted the road not travelled as an alternate life - the life unlived, you and your avatar. These can be plotted on the location diagram from the first script drama analysis article (Karpman, 1968): we can overlay unconscious relational patterns and other memes that arise along the way.

To create the feelings in existential diagrams the words must be chosen to evoke the maximum sense of the heart-breaking struggle and euphoric delights as one rises and falls in their wished-for existence through life.
We could postulate other existential diagrams. One experimental diagram could put oneself in the centre of concentric circles of varying clarity and thickness and labelled for the known and unknown barriers one has to work through to finally experience freedom. An example of that could be done with the nested Darwinian triangles (Figure 15). There are many other existential models and pictographs that can be created, such as a seeker being trapped in impossibly confusing mazes, each labelled with the antagonist person in their life; or the drawing of frightening and unfamiliar worlds without resources or help; or walking on crumbling bridges; or teetering on the wobbly ladder to nowhere; or facing some menacing thing that might come up to test them in a nightmare. In a workshop people can be asked to create their own original existential diagram and then share them with the group (if they want to).

The Existential Triangle 3.0. The Life Path of the Victim

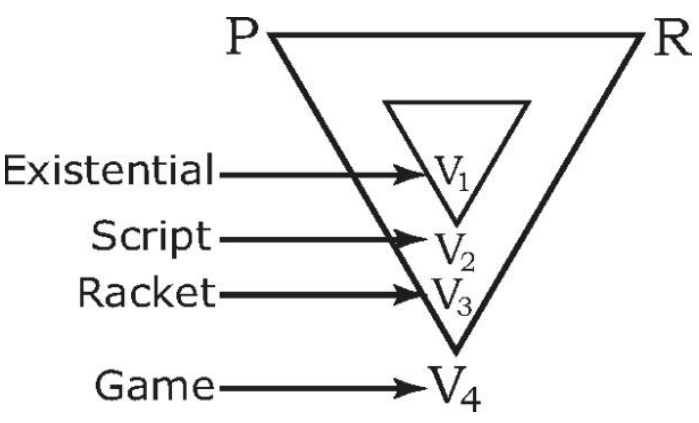

Figure 12: The Existential Triangle 3.0 - The Life Path of the Victim

\section{Four steps in the Victim path}

Figure 12 illustrates the path of an Existential Victim in life, for a position whether inherited, pre-verbal or only vaguely experienced (V1), but not decided on, that nonverbally manifests itself in infancy but later influences a script decision (V2) to join the family games. Then, in the present, under distress, these old feelings emerge as the racket (V3), are used to set up a life game (V4) to collect stamps for the underlying payoff, which is to prove, solve, or remain in the early V1/V2 positions.

The earliest $\mathrm{V} 1$ position may be intriguing for a wide range of interests, in past lives work, ESP [extra sensory perception], astrology, and hypnotic trance work.

The four-step life model is useful for therapists and counsellors as four points to consider touching bases on in therapy, that connect the psychological levels and the social levels in TA. It can be a working model to link the past to the present as steps and clear layers to life, or as a plan and an approach for a complete 
therapeutic experience beginning at any point and working in either direction. It can be used as a model in armchair theoretical discussions of the pros and cons of inherited tendencies in humans. As a simplified teaching model, V1 suggests unknown depths to the knowledge in human scripting. The illustration can be taught to generate insight for employees in the organisational and educational fields of TA - and possibly taught in TA 101 introductory courses.

\section{The Two Other Existential Paths}

The Victim path shown is the most useful existential drawing for psychotherapy, but the other two specific drawings could also show an introductory path from the other two corners:

The Rescue Path. This can be the life script of someone born too loving, too passive, too empathic, and too dependent, who continually gets taken advantage of in life and endures many disappointments and betrayals if they stay in their scripts; but if challenged successfully, script free, they can make great use of their tendency for the wise and intuitive helping of others and themselves.

The Persecutor Path. This can be the inherited position of someone who is born too aggressive with too much adrenalin in their inherited biological system, easily triggered, existing in duality with too little noradrenaline as a balance. If the energy is not channelled into drives for success and accomplishments, and they stay in script, they may face control issues when setting up games of belligerent acting out, and getting routinely fired from jobs and relationships, and in extreme cases ending up in prison. They have to continually adjust to the consequences they receive from others throughout a lifetime while coursing through the life path of The Persecutor.

\section{Existential Life Continuums}

Let us further experiment with some diagrams (Figure 13) in a theory challenge to bring right brain emotions over to the left-brain system. The examples below use varying arrow directions and plot points to be marked with an $x$ so a person can conceptualise their advancing and retreating existential patterns.

The first continuum of Failure <-> Success shows a desperate person coming into therapy in a one-way shame spiral falling from their heights of Success to their depths of Failure. The second person's continuum is at a midway point vacillating between Insignificance and Pride in their therapy contracts. The third has almost reached their goal in therapy on their hard-won path from Isolation to Attachment. The fourth and fifth show other variations of possible continuum elements.

As an experiential exercise, the reader can ask themselves where they reside on those scales in their own life, and ask if they felt anything inside when plotting the points - a feelings test for validity.

Continuums can also be plotted to represent progress in the primary contract in therapy. People can plot any of their own life journey continuums. The arrows and the plot points can change with time and circumstance. In group therapy it could be taped up on the wall with the other contracts. The reader is asked to write down their own life goal continuums and consider whether they are on track - or has it changed and if there are halting barriers to draw on the line.

Each of the Goulding and Goulding (1976) redecision injunctions can have a goal driven continuum, such as Don't Be You at $25 \%$ on an axis advancing toward $100 \%$ of personal identity and empowerment. Another person can enter therapy feeling existential meaninglessness in life - that there is no true reality, everything is fantasy, and come in seeking concrete purpose. Each person has an existential story.

The positions on the left can represent the unexamined life; the points on the right can be one's contract in therapy, or contract with oneself.

Berne's (1972) six time scripts can be diagrammed on continuums. There could be the emptiness or joy and freedom as opposites in an aging open-ended time scrip, or the continuing frustrations and failures of the Over and Over script.
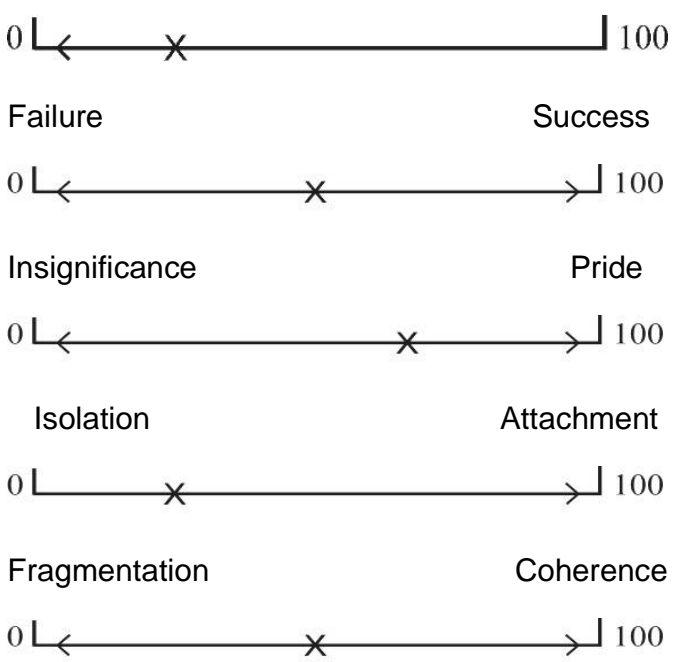

Enmeshment Autonomy

Figure 13: Existential Life Continuums

\section{Existential Positions}

Various TA treatment approaches have discussed the existential crisis one faces in life. The Process Therapy Model (Kahler, 2008) suggests six existential questions for each of the base six personality types: The Believer - Am I worthy? The Feeler - Am I loveable? The Doer - Am I alive? The Thinker - Am I prepared? The Funster - Am I acceptable? The Dreamer - Am I wanted? 


\section{Script Energy Systems}

\section{Script Energy Systems}

We can consider these as energy that begins inside and moves out, with three points of origin.

Freudian Energy Systems.

We can ask from where arises the fuel that fires the script? Is the energy split between the twin Freudian drives of libidinal Eros for script-free living, and the destructive Thanatos of scripted living?

The Freudian drama triangle (Figure 14) repositions the Freudian system into the equivalent corners of the drama triangle. We see all script energy beginning inside the Freudian boiling cauldron of horrors and undesirable impulses that is the id, which can be represented by the unwanted and avoided $\mathrm{V}$ in the diagram; an id long repressed by the superego $(P)$, but eventually turned into social accessibility by the friendly ego $(R)$ who can choose from a dozen Freudian ego mechanisms of defence where appropriate, including sublimation, rationalisation, intellectualisation, reaction formation, displacement, suppression, projection, and dissociation, to name a few. Figure 14 shows the Freudian psychodynamics placed within the drama triangle in the ongoing struggle of psychological energy at the deepest level. Unfortunately for science, these are not measurable in any known anatomical structures.

$\mathrm{P}$

$\mathrm{R}$

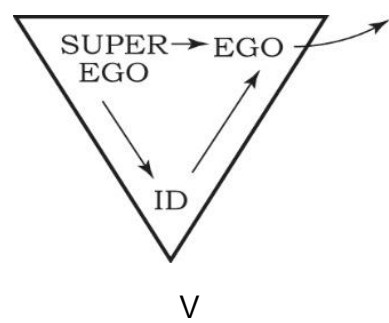

Figure 14: The Freudian Drama Triangle

The Freudian Drama Triangle. The id can be the energy source in the engine that fuels the fire of the unconscious, as an instinctual primitive life energy source that never quits. The drama triangle in its design is a fluid three-part energy system and can be used to illustrate connections between a wide range of psychodynamic internal systems, making a visual connection between a three-point Freudian theory and a three-point TA games theory.

These drives are the hidden engines fuelling script choices so they are included in this script paper. The illustration traces the pathways of Freudian drive energy. We can ask which script choices are made in deference to the id, which script choices were adjusted by the ego, and which script choices were made to appease the superego? Likewise, are all Parent, Adult and Child ego states involved in all script decisions. Are all of them watching?

Following the steps in the diagram, we have: 1). The repressed id - the Victim of unwanted and avoided impulses, starts below in the Victim in the low basement corner at the id; then 2). presses itself upwards to get help from the Rescuer ego to gain its expression (cathexis) in the outer world. There is release, the escape arrow in the diagram, by the ego mechanisms of defence; but then 3 ). the Persecutor superego comes in as a harsh social level moral regulator preventing both the ego and id from its full expression, and the frustrated id returns to the Victim position, thwarted, in a psychodynamic repeating cycle of unconscious life forces.

Theory Bridges. This drama triangle offers a theory bridge between the Bernian transactional analysis model and the Freudian psychodynamic model. Another way of linking the two models was illustrated above in transference Figures $7 \mathrm{a}, 7 \mathrm{~b}$ and 8 that show that the Freudian transference and countertransference models can be equally illustrated as TA crossed transactions in the ego state model.

\section{Three Spiritual Unconscious Drives}

Another way of looking at unconscious drives, here ruling us like ancient Greek Goddesses, are described by (English, 2008): 1. Survia (for Survival), 2. Passia (for Passion - creativity); and 3. Transcia (for Transcendence - spirituality). Passia motivates us best.

\section{The Darwinian Triangle: Energy Arising from Three Survival Instincts}

The story of the Darwinian Triangle dates back to the earliest uses of the drama triangle in what became known as the compassion triangle. During game analysis work with couples, when analysing a Persecutor role for instance, to gain a deeper understanding of all the motivations, I would automatically inquire in what way was the person also a Rescuer and a Victim in that situation. Both parties would always be able to find something sympathetic in the two other motivations.

By asking that question I was using basic TA in Berne's ego state model where all three ego states are all present at once as visually connected in the diagram, and the ego states can all be fluidly used in either positive or negative ways, and when doing an egogram, all five ego state are all visible at once on someone's persona. So, I applied that principle to the drama triangle. The three corners are always there in any game situation. But a client once asked me directly, "How do you know all three roles are present at once?" That got me wondering, what would be the theory behind that. Was there proof? Years later, one evening while watching the History Channel on TV, a 


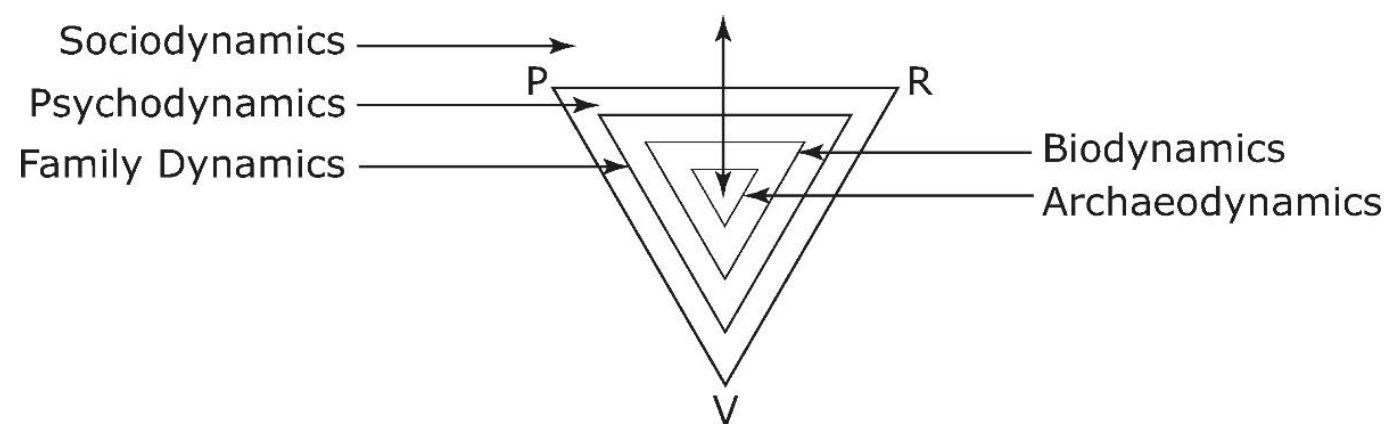

Figure 15: The Darwinian Triangle 4.0

baby elephant was being stalked by a tiger. The parent elephants immediately formed a protective circle around the baby, everyone roared, and drove the tiger away. All three corners of the drama triangle had to be present in order to protect the baby's survival - to live again and begin another generation, and another, to this day.

The protective parent keeps the offspring (and family genes) alive only by the instantaneously triggering of all three instinctual reactions to the threat:

a. The Rescuer instinct is needed to want to rescue their precious offspring, their family, and self;

b. The Victim Instinct is needed to empathically experience the child's danger, and the alarm at the threat to self, and the entire family existence;

c. The Persecutor instinct is needed to fight off a threatening predator, and that aggressive energy is also needed to compete for better food sources.

This required a new theory that there are actually three parts to the traditional two-part Flight $(\mathrm{V})$ or Fight $(\mathrm{P})$ concept - with a third F - Fix it - the Rescuer $(R)$ and protector role. The instantaneous alarm reaction of all three drama corners is the biological equivalent I looked for to prove the rule of the ever-present threesided roles of the compassion triangle.

\section{Nesting the Darwinian Triangle}

I had been looking already at theoretical diagramming of some layers in the drama triangle, by placing the social level visibly on the outside of the triangle, the psychological level tucked just inside the inner corners of the triangle, and the family level to visualise the family of origin triangle discussed previously. Now I could bring in the Darwinian level at the core of the nested triangles.

\section{The Biodynamic Transactional Level}

There was one more space to fill, that would go inbetween the last two; so in there I put the somatic energy level. I called that the biodynamic level. It can also be called the biologue, because the cells are always transacting with each other. Cellular survival includes all three corners of the drama triangle which by design are always transacting with each other in a biologue and trialogue (never a unilogue).

The biodynamic level is the deepest interior level where the cells are now transacting to maintain homeostasis. The fluids need to be continuing from the Re-supply (R) cells; to the Reception (V) cells; and they also need the Restriction $(P)$ cells to prevent oversupply or over-absorption. An example of this is the SSRI antidepressant medication where re-uptake (V) of serotonin is inhibited by $P$, the SSRI medicine, to maintain optimal levels of serotonin.

The DNA level is where the genes may present three functions, either to prove dominant or destructive $(P)$; or transcendent to evolve to a higher order of being one day $(R)$; or as unsuccessful or outdated genes $(V)$.

\section{A Healing Path}

At a workshop someone pointed out that there was still a tiny little empty space at the centre that I forgot to fill up. The speculation was that this was where the soul resides, or the God within us, or Perfection, or peacefulness and goodness and wholeness at our core with which we had lost touch. So the escape arrow upwards was added. The vertical escape arrow shows the layers of challenge and struggle the peaceful soul has to transverse in its path to survive into present reality. In therapy we classically repair the path back from the top and downward, one by one, through each of the racket and game layers to get to the centre of peace. Or, with love and happiness, or through meditation, body awareness and mindfulness approaches, but not street drugs, we can perhaps begin healing the centre first, with the healing energy spreading upwards and outwards to heal what is damaged at each stage in the surrounding levels.

Combining all these levels together in a Darwinian triangle we may be looking at the psychological equivalent of the fleeting goal in physics of $A$ Theory of Everything (Karpman, 2014). 
Script Social Energy Systems

I have written above about needs that must be discharged from within outward as a primary goal driving us. There are also needs that must be received from the outside world as a primary goal. Some energy sources to gather from the outside include:

Outward Drive for Strokes, Love, Belonging, Purpose, Fulfilment, Worth, Harmony and Reassurance - and more!

On the scales of life, these positive rewards can motivate us to bring a balance to a negative script, and provide time structuring used for strengthening oneself to achieve these benefits in recognition from others, and get more.

\section{Outward Drive to Receive the Script Payoffs}

The child's early script positions and script decisions serve as a protective shield over disruptive childhood memories, similar to the Freudian counter-cathexis wall that protects the ego from the internal disruptions of the id. So we seek outward confirmation in the script payoffs that our defence mechanisms are still holding firm and will keep protecting us from re-experiencing our repressed fears.

\section{Outward Motivation to Gather Satisfaction of the Six Hungers}

Berne (1970) described six hungers basic to human needs: Stimulus, Recognition, Contact, Sexual, Structure, and Incident. The script motivation is to reach outwards to satisfy these hungers and bring the satisfaction back to the self.

\section{Outward Motivation to Find Existential Answers}

There are inward questions about life and existence that concern the thoughtful mind. The soul seeks answers such as human viability, purpose, adequacy and worth, with ruminative questions such as Am I Wanted, Am I Worthy, Am I Adequate, Am I Prepared?

\section{General Psychology and Spiritual Paths}

These have their own motivational drives, such as Maslow's (1968) hierarchy of needs, often presented as a pyramid of steps leading one up to achieve the summit of personal self-actualisation. There are many other systems with striving goals and motivations, Nirvana, etc. to build a positive script to replace a negative script.

\section{The External Advantages of Games}

Additionally, Berne (1964) listed six 'advantages' for playing games that would energise someone's drive for contacting others. Games advance the needs of script, including providing time structuring, getting positive and negative strokes, confirming the script positions, and gathering the internal and external social and psychological advantages of games.

Similarly, just as the Freudian ego mechanisms of defence protect against pressures from within, likewise Bernian social games are outward defence mechanisms to protect oneself against stroke deprivation from others. Every game is a controlled defence mechanism to prevent surprise hurt, fear and disappointments in relationships - but we will settle for anything in between.

\section{Three New Script Reinforcement Models}

Scripts need to be reinforced to maintain the protection that they were designed to provide - and eventually they are reinforced by habit. We know that scripts get reinforced - but how do they get reinforced? In this section we provide a missing link in TA script theory: three script formula systems

\section{Script Formula G}

Berne (1972) never created a script formula as he did a game formula. I offer below a useful short form Script Formula G (G for Game) (Figure 16); and a daily use long form Script Formula P3 (Figure 17).

These are used to fill out script theory with more simplified and useful formulae that follow Berne's scientific TA mandate for TA theory that was to trim ideas down to their simplest form using Occam's Razor. 26 of his other rules have been previously recorded (Karpman, 1972, 2014).

Script Formula $\mathrm{G}$ is the most mathematically elegant of the two formulae because it reduces script theory to just three moves, as the drama triangle reduces games to just three moves. The initial letters in this scientific Formula $G$ below represent script POSITION-- $\rightarrow$ script GAME-- $\rightarrow$ script PAYOFF and back again.

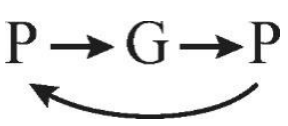

Figure 16: Script Formula G

It is simplified too for teaching purposes, showing the progression of the script from the early script position $(P)$, which sets up the roles for the script game $(G)$, when played later in life and then going back to the early childhood script payoff $(P)$, reinforced, and then can swing back to start all over again. In a safe redecision therapy setting, the client can repair those early script positions which would then abort the remaining game sequence which then cancels the payoff.

\section{Script Formula P3}

Script Formula P3 (Figure 17) now links together three stages of scripting - the beginning, middle, and end. This formula looks into the actual daily situations and transactions, step-by-step, in nine steps that bring about a completion of the script sequence. 
PPP1 ---> PPP2 ---> PPP3

Figure 17: Script Formula P3

The Three P's of Script Position (PPP1)

We start with a beginning triplet that sets up the script position in life. For memory and teaching purposes, they will all start with the letter $P$. The early family scripting begins with:

Persuasion - a compelling home environment requiring a change in the child's world view;

Position - in that environment the child needs to decide on a protective script position to take in life;

Plan - how will the script be carried out. In TA script history, the first plans offered included following the life story of the favourite family fairy tale (Karpman, 1968); Berne's (1966) palimpsest, Berne's (1972) six time scripts, or Steiner's (1974) mindlessness, lovelessness, and joylessness scripts.

The Three P's of Script Promotion (PPP2)

I call this intermediate step in script analysis the three P's of Script Promotion: Pick them, Provoke them, or Perceive them, which pinpoints just how someone finds, keeps or entices the players to fit into their script games. This makes the link between step one and step three of script theory. Redecision therapy often begins after the recent game scenes are already in play, then a retracement begins that leads to the earliest scenes. The day by day link-up can be explained to happen in one of three ways:

Picking the suitable game player to team up with; or -

Provoking the person until they eventually play the needed complementary role; or -

Perceiving them falsely with projections, transferences, error, and misreading egograms and then treating them accordingly even if they never fit the roles.

The Three P's of Script Cure (PPP3)

As mentioned, this was the first script formula developed in Eric Berne's San Francisco 202 seminar, and assembled by Claude Steiner.

Permission (Berne, 1972) - to break the family curse,

Protection (Crossman, 1966) - monitoring the client safely through any setbacks,

Potency (Steiner, 1974). For the permission to succeed, the therapist needs to be more potent and believable than the bad parent.

\section{The Miniscript Drama Triangle}

Shown in Figure 18, this is a vertically pointed drama triangle, a modification of the original miniscript triangle (also vertically pointed) (Kahler with Capers, 1974) which demonstrated a new theory that there is within us a second-by-second life script reinforcement cycle. This is initiated at the top Rescuer corner by a triggering of one or more of the five observable script drivers: I'm OK if I.... Be Perfect, Be Strong, Try Hard, Hurry Up, or Please Others. These move quickly in a clockwise direction around the points of the triangle and soon to return to the endpoint, the Victim point again.

However, in this modification for script games, the script reinforcement cycle begins at the feeling rackets at the Not OK Victim position. The racket may arise from among a collection of trading stamps, unmet needs and hungers, somatic or preverbal or existential positions, or other suppressed pains and desires. They manifest as rackets because it is within the game system and inside a drama triangle, and needing to be satisfied and made (temporarily) OK by the rescuing driver.

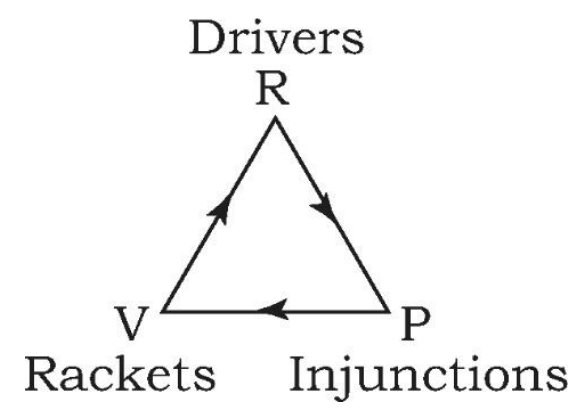

\section{Figure 18: The Miniscript Drama Triangle}

In this sequence, to repair the racket, one moves up to the Rescuer I'm OK if.... position and hopefully the drivers will be used to fix the problem - after all, they seem to be known as successful efforts. For example, hopefully if one becomes Perfect and thinks of everything, they will be OK. But all the drivers have built-in failures. No one can Be Perfect or Please Everyone, and eventually they make disappointing mistakes. These drivers seemed to be OK counterscript drives for OKness, but these particular five drivers are unsustainable and the person fails.

The person then drops down to the script injunction, or stopper level. That injunction can be created or imagined from within or without from others. For example, if one has a Be Strong Driver followed by a Don't Be Close injunction at the lower Persecutor corner, that conflict is unsustainable. One is chased back to the Victim position to begin the cycle all over again. This stirs up the racket to fix itself again and the cycle repeats over and over. All three - rackets, drivers and injunctions - are reinforced once again with each swing around the triangle.

\section{Four Useful Teaching Triangles}

In addition to the previous redecision, transference and existential triangles, there are four script drama triangles (Figures 19, 20, 21, 22). These are simplified for teaching and training purposes in ways that 
combine several schools of transactional analysis into single easy-to-read diagrams. These can be used to illustrate the psychological position that there are many unknown layers to human behaviour and can be applicable to all the fields of TA application: Psychotherapy, Counselling, Organisational, and Educational.

These novel drawings use the drama triangle to connect games to scripting in a single diagram. They organise four principal TA approaches: games/the drama triangle, rackets, injunctions, and miniscript drivers, all in simplified theory diagrams that can be drawn on a blackboard. The Freudian system of three layers of consciousness can also fit into the three levels of the drama triangle.

Figure 20 is another three-tiered basic TA diagram that places games, rackets and script in a single diagram. The outside space of the triangle is for the observable social level game, and the internal spaces are for the unobserved psychological levels during the game playing. The family triangle in the centre is to tie in script theory.

Figures 21 and 22 illustrate similar tiers for social and psychological levels, and for conscious, subconscious and unconscious levels.

\section{Discussion}

\section{Brainstorming New Theory}

In the dual purpose of this paper we have sketched out many new ways of looking at how games are involved in scripts, all the while demonstrating the rules and results of brainstorming that require there be no critical judgment or dismissal of ideas during the process as random ideas emerge.

Ideas on these pages can now be judged, and observed, used, developed, or unused - or destined for the dustbins of history.

Brainstorming appeals to a puzzle-solving and curious mind who will join in the shared excitement of a group project with an exciting new purpose. Eric Berne's Tuesday night 202 training seminars in San Francisco in the 1960s attracted this type of idea-seekers with a group purpose of developing further his revolutionary new science of transactional analysis. A genius leader will keep people professionally and personally interested and involved, and confirming the maxim that top organizations will attract and hold onto their best talent. In another era, writing on this experimental scientific mind, Sigmund Freud wrote: "I am not really a man of science, not an observer, not an experimenter, and not a thinker. I am nothing but by temperament a conquistador, an adventurer . . . with the curiosity, the boldness, and the tenacity that belongs to that type of being." (Edmundson, 2007, p.26).

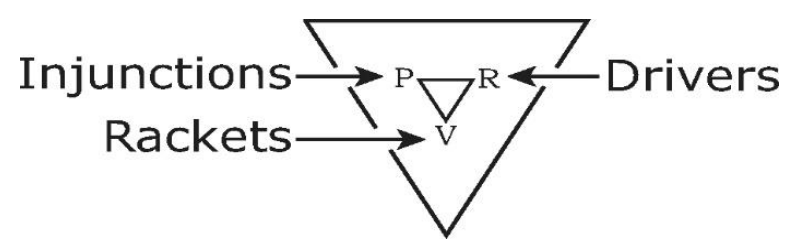

Figure 19: The Script Drama Triangle (Karpman, 2009, p.114)

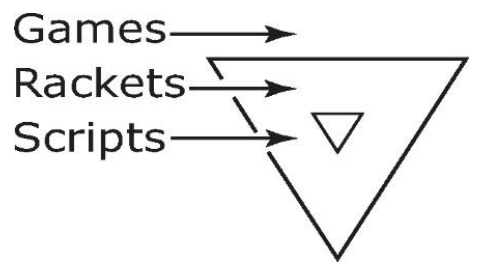

Figure 20: The Games, Rackets, and Scripts Triangle

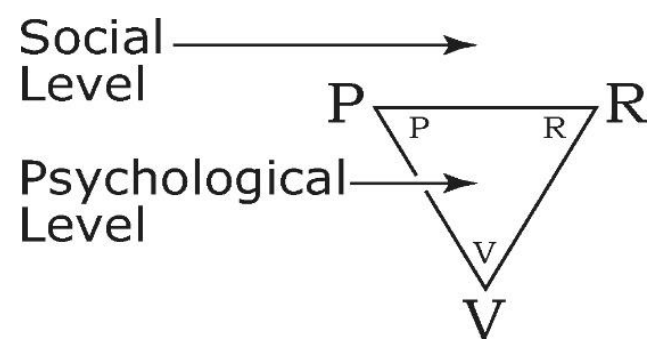

Figure 21: The Social Level and Psychological Level Drama Triangle

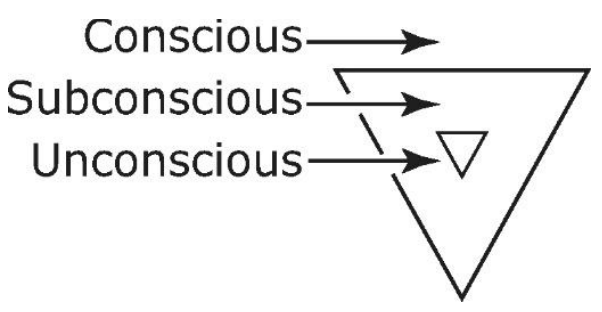

Figure 22: Three Freudian levels of consciousness drama triangle

Which ideas will last?

Which ideas will last and which will not may all be up to fate and chance. The drama triangle began as a playful sports diagram (Karpman, 2014) but spread by chance by grassroots word-of-mouth and went viral well beyond the circles of transactional analysis without any directed promotion. The gestalt therapy method spread mostly by word-of-mouth as Fritz Perls did not want an international structure. Darwinian theory suggests that what wins the future will be determined by the survival of the fittest. What would be determined by fate was best written by William Shakespeare: "If you can look into the seeds of time, 
and say which grain will grow and which will not, speak then unto me." (Coursen, 1997 Act 1, Scene 3, Line 58 $-60)$

\section{The Institutional Protection of Ideas}

Healthy organisations create fixed structures to protect their best ideas. Berne and Freud more than others created international organisations with officers, committees, journals and conferences, with rules and rewards and incentives to motivate their membership and maintain their future development and presence. The ITAA protected their best theory and therapy ideas by agreeing on a basic set of core concepts protected by a Training Standards Committee. Trainees need to learn and use these ideas effectively in order to pass the certification process and get rewarded upward in the ITAA ranks. But some theory may not last when internecine politics eventually plays a part in what survives and what does not in an organisation, with insider games being played (Karpman, 1981, 1991, 2006).

\section{Berne's System for Idea Permanence}

Berne had another system to maintain the usability and integrity of inventions. He stressed that original ideas needed to be written up in a way that would be lasting. With foresight he preached to his trainees to use all four rules for doing that.

\section{1. "Don't say anything you can't diagram."}

2. "Don't say anything that has ever been said before."

3. "Always use Occam's Razor of Scientific
Parsimony."

\section{4. "Always write it up in layman's [sic] language."}

And the writing should be "understandable to an eightyear-old child, a Midwest farmer, and an MIT professor." For example, the drama triangle has survived only because it fulfils all four criteria. If it was written up in several tedious paragraphs of Parent scholarly 'psychobabble' words, where would it be now? It would now be in that 'dustbin of history.'

Occam's Razor was most important and it has been widely used throughout the history of great science. That meant reducing a brilliant concept to a single unit, so that people could use it and remember it, and not want to add barnacles on it later, and could make pithy theory like Einstein's $E=m c 2$.

Taking Occam further, in the early days Berne taught that the one-session script cure was the goal for TA treatment. He talked of the single triple bull's-eye transaction to all three ego states that could swiftly cut the single Gordian Knot of the commonplace lengthy therapies. He wanted to find and pull out the splinter in the foot that would cure the leg ache that led to the backache that led to the presenting headache. He gave us our TA single vision 'To Cure Patients Faster,' and by using Occam's Razor we could seek simpler tools to more quickly reach that goal.

This teaching influenced early TA therapists and led to Bob Goulding's discovery of a single bull's-eye redecision therapy process that creatively linked Berne's scientific mandate for TA 'Don't say anything you can't diagram' with Fritz Perls' experiential gestalt therapy opposite position of 'All thinking is a head trip'. That brave juxtaposition eventually led to Goulding and Goulding's' inclusion of both TA and a gestalt experiential treatment approach to achieve the important scientific TA list of 12 core injunctions.

Steve Jobs, Apple Computer's co-founder genius, had this to say about the course of history: it could only be determined looking backwards and connecting the dots that led to the present. He could trace his myriad life adventures as all being important to his eventual creation of the iPhone. "Again, you can't connect the dots looking forward, you can only connect them looking backward. So you have to trust that the dots will somehow connect in your future." (Jobs, 2005, para 9)

This article is all dots; the use to be determined in time. I did connect all the dots leading up to the Darwinian triangle, with many levels of drama invented over the years, to eventually get to the Darwinian proof of the automatic three roles in the compassion triangle that would date back to Darwinian three survival instincts, all necessary at once.

Berne on the Power of Scripting.

In conclusion, l'll add one more quote, from Berne on the power of early childhood scripting, from the introduction of his final book: "The history of human scripts can be found on ancient monuments, in courtrooms and morgues, in gambling houses and letters to the editor, and in political debates, where whole nations are talked down the righteous road by someone trying to prove that what his parents told him in the nursery will work for the whole world." (Berne, 1972 p.53).

Stephen B. Karpman, M.D. is a Teaching and Supervising Transactional Analyst and was twice vice president of the ITAA serving on the Board of Trustees for 11 years. Dr. Karpman teaches widely across the United States and abroad. Academically, he is an Assistant Clinical Professor of Psychiatry at UCSF in San Francisco, where he also has his private practice. His articles, many out of print, are available on his free web site at www.KarpmanDramaTriangle.com. All comments to this article are invited by e-mail at egostates@aol.com or on the web site.

\section{References}

Berne, E. (1964). Games people play: The psychology of human relationships. New York: Grove Press. 
Berne, E. (1966). Principles of Group Treatment. New York: Oxford University Press.

Berne, E. (1966-70). Personal communications. San Francisco Transactional Analysis Seminars, San Francisco.

Berne, E. (1970). Sex in Human Loving. New York: Simon \& Shuster.

Berne, E. (1972). What do you say after you say hello? The psychology of human destiny. New York: Grove Press.

Cassius, J. (1975). Bodyscripts: Collected papers on physical aspects of transactional analysis. Memphis TN: Author.

Childs-Gowell, E. \& Kinnaman, P. (1978). Bodyscript blockbusting: A transactional approach to body awareness. San Francisco: Trans Pubs.

Cornell, W.F. (1975). "Wake up, sleepy": Reichian techniques and script intervention. Transactional Analysis Journal, .5, 144-147.

Coursen, Herbert (1997). Macbeth: A Guide to the Play. Westport, CN: Greenwood Press.

Crossman, P (1966). Permission and Protection. Transactional Analysis Bulletin, 5(19), 152-154.

Dusay, J. (1972). Egograms and the Constancy Hypothesis. Transactional Analysis Journal, 2(3), 37-41.

Edmundson, M. (2007). The death of Sigmund Freud. New York: Bloomberg.

English, F. (2008). What Motivates Resilience after Trauma?, Transactional Analysis Journal, 38:4, 343-351, DOI: $10.1177 / 036215370803800409$

Erskine, Richard (1980) Script Cure: Behavioural, Intrapsychic and Physiological. Transactional Analysis Journal 10 (2) 102-106

Goulding, R. L., \& M. M. (1976). Injunctions, decisions, and redecisions. Transactional Analysis Journal, 6, 41-48.

Goulding, R.L. \& M.M. (1979, revised 1997). Changing Lives Through Redecision Therapy. New York: Grove Press.

Hargaden, H., \& Sills, C. (2002). Transactional analysis: A relational perspective. London: Brunner-Routledge.

Isaeva, N. (2011). Personal communication, Bilbao, Spain Jobs, Steve (2005). Text of Steve Jobs' Commencement Address at Stanford University, Stanford University News June 14

Kahler, T. (2008). The Process Therapy Model: The Six Personality Types with Adaptations. Little Rock, AK: Taibi Kahler Associates
Kahler, T., (2019). Personal communication.

Kahler, T. with Capers, H. (1974). The miniscript. Transactional Analysis Journal, 4(1), 26-42.

Karpman, S. (1968). Fairy tales and script drama analysis. Transactional Analysis Bulletin, 7(26), 39-43.

Karpman, S. (1972). ABC's of hooking the Reader's Child. Transactional Analysis Journal, 2(1) 8-12.

Karpman, S. (1973). 1972 Eric Berne Memorial Scientific Award lecture. Transactional Analysis Journal, 3 73-76.

Karpman, S. (1974) Overlapping Egograms. Transactional Analysis Journal, 4:4, 16-19.

Karpman, S. (1975). The Bias Box for competing psychotherapies. Transactional Analysis Journal, 5(2). 10711.

Karpman, S. (1981). The politics of theory. Transactional Analysis Journal. 11(1), 68-76.

Karpman, S (1985). Make your wildest dream come true. Bulletin of The Eric Berne Seminar, 5 (2) 18-23. http://karpmandramatriangle.com/pdf/wildestdream.pdf

Karpman, S. (1991). Notes on the transference papers: transference as a game. Transactional Analysis Journal. 21(3), 136-140.

Karpman, S. (2006). Lost in translation: Neo-Bernian or Neo-Freudian? Transactional Analysis Journal. 36(4), 284302.

Karpman, S. (2009). Sex Games People Play: Intimacy Blocks, Games, and Scripts. Transactional Analysis Journal, 39 (2) $103-116$.

Karpman, S. (2014) A Game Free Life: The New Transactional Analysis of Intimacy, Openness, and Happiness. San Francisco: Drama Triangle Publications.

Kupfer, David \& Haimowitz, Morris (1971) Therapeutic Interventions Part 1 Rubberbands Now. Transactional Analysis Journal 1:1 10-16.

Maslow, Abraham Harold (1968) Towards a Psychology of Being $2^{\text {nd }}$ edit New York: Van Nostrand.

McNeel. J. (1976). The Parent Interview. Transactional Analysis Journal, 6, 61-68.

Penfield, W, and Jasper, H. (1954). Epilepsy and the functional anatomy of the human brain. Boston: Little, Brown, and Company.

Steiner, C. (1974). Scripts People Live. New York: Grove Press.

Steiner, C. (1966). Script and Counterscript. Transactional Analysis Bulletin 5(18) 133-135. 